\title{
FERMENTATION WITH LACTOBACILLUS STRAINS FOR ELIMINATION OF GLUTEN IN WHEAT (TRITICUM AESTIVUM) BY-PRODUCTS
}

\author{
Vijole Bradauskiene ${ }^{1,3 *}$, Lina Vaiciulyte-Funk ${ }^{1}$, Edita Mazoniene ${ }^{2}$, Darius Cernauskas ${ }^{1}$ \\ ${ }^{1}$ Food Institute, Kaunas University of Technology, Radvilenu road 19, Kaunas, Lithuania, e-mail: vijole.bradauskiene@ktu.edu \\ ${ }^{2}$ Polymer Science and Technology Department, Kaunas University of Technology, Radvilenu road 19, Kaunas, Lithuania \\ ${ }^{3}$ Food Technology Department, Faculty of Technology, Klaipeda State University of Applied Sciences, Bijunu street 10,
} Klaipeda, Lithuania

\begin{abstract}
Recently there is an increase in the number of consumers with gluten intolerance that causes expanding of the demand for gluten-free products. Gluten-free diet is unbalanced and usually has a higher percentage of calories from fat, less of carbohydrates, as well as low intake of non-starch polysaccharides. To solve this problem, new strategies are looked for to eliminate gluten in products of wheat and other cereals and to make them more balanced. Fermentation with lactic cultures and/or enzymes enables to reduce the gluten content in wheat flour. However, this process takes a long time, it is complicated to control, and hydrolysed gluten loses its technological properties. The purpose of this work was to find another way of removing gluten residues: first remove gluten from wheat by wet fractionation, then hydrolyse gluten residues in the remaining fractions by using biotechnological measures. The fractions of starch, fiber and bran had an initial gluten concentration of $85-33750 \mathrm{mg} \mathrm{kg}^{-1}$. For eliminating the gluten residues, they were fermented with four probiotic strains separately: Lactobacillus plantarum P-1, Lactobacillus brevis R-1, Lactobacillus acidophilus 308, Lactobacillus acidophilus 336. Short (12 hours) and long fermentation ( 24 hours) at 30 and $37{ }^{\circ} \mathrm{C}$ was used. Gluten was degraded in wheat starch to below $20 \mathrm{mg} \mathrm{kg}^{-1}$ using Lactobacillus plantarum in short time, other strains performed better using long fermentation. In conclusion, it could be stated that sourdough-based biotechnology could eliminate the immunogenicity of wheat by-products and to improve the quality of life of celiac patients.
\end{abstract}

Keywords: wheat, gluten, hydrolysis, sourdough, Lactobacillus

\section{Introduction}

Wheat is one of the most popular cereals in the world, however, gluten proteins of wheat are responsible for very common allergic reactions in populations, leading to immune disorder and non-celiac gluten sensitivity (Gujral et al., 2012; Kang et al., 2013; Catassi et al., 2014). Currently, the only therapy is a strict, lifelong gluten-free diet (GFD). Compliance with a GFD is an extremely challenging task, given a number of problems related to poor quality of gluten-free products compared to their gluten-rich counterpart (Do Nascimento et al., 2017) as well as these products are more expensive (Stevens, Rashid, 2008). Patients with celiac disease are looking for alternatives and are using products from gluten free materials such as corn, rice, millet, buckwheat, amaranths and potatoes. The diet of these patients is unbalanced and have a higher percentage of calories from fat and less from carbohydrates, also in GFD was obtained low intakes of non-starch polysaccharides (Thompson et al., 2005; Wild et al., 2010). Products made from naturally gluten-free raw materials resulted in breads often having inferior textural and sensory properties compared to the corresponding gluten-containing products (Hager et al., 2012; Miranda et al., 2014; Pellegrini, Agostoni, 2015). To resolve this socioeconomic problem, new strategies are looked for to eliminate harmful gluten from wheat and other cereals and to produce balanced products with good sensory properties (Greco et al., 2011; Nionelli, Rizzello, 2016).

Wheat gluten fragments (peptides) remain intact during digestion. They penetrate through the small intestine wall and initiate antigenic cellular immune responses. There is no immune response if the gluten is hydrolysed to peptides, which contain less than nine amino acid residues. Research on the use of biological measures in wheat products to eliminate or reduce the immune toxicity of gluten proteins is being actively pursued in the last decade. Numerous studies (Di Cagno et al., 2008; Giuliani et al., 2016; Gerez et al., 2012; Loponen et al., 2007; Romanová, Urminská, 2017; De Palma et al., 2010; Stefanska et al., 2016) were carried out using lactic cultures - their individual strains or various combinations. They focus on probiotic strains' possibilities to decrease the toxicity of wheat flour, but there is a lack of informationon on biological measures to completely eliminate gluten from wheat processing products.

Sourdough fermentation with lactic acid bacteria (LAB) can improve the texture, palatability, aroma, shelf life and nutritional value of wheat breads (Guerzoni et al., 2011), texture and palatability of whole grain, fiber-rich or gluten-free products, stabilise or increase levels of various bioactive compounds, retard starch bioavailability and improve mineral bioavailability (Katina et al., 2005; Moroni et al., 2009). LAB degrade celiac active gluten peptides, because some species of $\mathrm{LAB}$ produce specific peptidases during growth, which are capable to hydrolyse hardly cleavable bonds between amino acids in proline-rich peptides (Vukotić et al., 2016). Selecting strains of LAB with targeted proteolytic effects is vital important (Stefańska et al, 2016).

The use of sourdough LAB was at first proposed with the aim of eliminating traces of gluten epitopes in 2002. Di Cagno et al. (2002) showed that selected LAB, possessing proteolytic activities, could efficiently hydrolyse the toxic peptides of gliadin in wheat sourdough. The pool of L. alimentarius $15 \mathrm{M}, L$. brevis $14 \mathrm{G}$, L. sanfranciscensis 7A, and L. hilgardii $51 \mathrm{~B}$ has a 
pattern of specialized peptidases capable of hydrolysing different peptide bonds that potentially include the proline (Di Cagno et al., 2004). Study of Di Cagno et al. (2008) highlighted the use of selected LAB consisted of Lactobacillus sanfranciscensis LS40 and LS41 and Lactobacillus plantarum CF1 to eliminate risks of contamination by gluten and to enhance the nutritional properties of GF bread.

Several studies were carried out using individual strains of LAB also. Sourdough fermentation using Lactobacillus sanfranciscensis (Thiele et al, 2004; Vermeulen et al, 2006) or Lactobacillus plantarum (Yin et al, 2015) showed a decrease in $\mathrm{pH}$ and resulted in hydrolysis and solubilization of wheat proteins.

De Angelis et al. (2006) showed the capacity of probiotic VSL\#3 preparation to hydrolyse extensively wheat flour. Probiotic product VSL\#3 including Streptococcus thermophilus, $L$. plantarum, $L$. acidophilus, L. casei, L. delbrueckii spp. bulgaricus, Bifidobacterium breve, B. longum and B. infantis strains was used in the fermentation of a mass with wheat flour in order to hydrolyse gliadin peptides and promoted almost complete hydrolysis of gliadin peptides. Patent Application WO2006/097415 (2006) describes a process for gluten degradation by means of the use of a complex mixture consisting of at least six lactic acid bacteria and/or bifidobacteria and long fermentation times (24-31 hours) also. After hydrolysis some gliadins were partially hydrolysed, but others were not susceptible to hydrolysis process. Lactobacillus plantarum CRL 775 and Pediococcus pentosaceus CRL 792 also hydrolysed gliadins during wheat dough fermentation (Gerez et al., 2012).

Romanová, Urminská (2017) described growth characteristics and intracellular aminopeptidases activities of Lactobacillus plantarum CCM 3627 and Lactobacillus brevis CCM 1815. The results confirm production of active proline aminopeptidase, which is important for cleavage of proline rich-peptides. Two strains: Enterococcus mundtii and Wickerhamomyces anomalus exhibited the potential to be used as probiotic for sourdough fermentation: they have shown the ability to tolerate low $\mathrm{pH}$, bile salt properties and hydrophobicity compared to other gluten-degrading yeast and bacterial strains (Sakandar et al., 2018).

Stefańska et al. (2016) have selected 11 LAB strains capable of hydrolysing gliadin in bakery sourdoughs. However, in all sourdoughs were found some polypeptides with IgE-reactive epitopes. Previous research has shown that fermentation with $\mathrm{LAB}$ reduces the amount of reactive gluten fragments, but does not reach the safe limit for gluten free products, which is $20 \mathrm{mg} \mathrm{kg}^{-1}$ (Standard 118-1979, 2015).

Fermentation with mixtures of selected lactic acid cultures in combination with fungal enzymes enable to reduce the gluten content in wheat flour to gluten free limit (Rizzello et al., 2007; 2014). However, this process takes a long time, it is necessary to control it in several stages, but hydrolysed gluten still loses its technological properties: enzymatic hydrolysis destroys the gluten network, reduces the elasticity of the dough and baked goods (Van Den Broeck et al., 2009).

In this work, it would be advisable to combine physical and biotechnological measures for the preparation of raw materials for the production of gluten-free wheat products: at first remove gluten from wheat by wet fractionation, then hydrolyse gluten residues in the remaining fractions by using LAB fermentation. Whereas the levels of gluten are low in the wheat by-products, it can be expected that the effect of LAB will be sufficient to eliminate it.

Wet fractionation of wheat could be done by centrifuging of the flour-water mixture in the laboratory according to Czuchajowska and Pomeranz (1993) as well as at industrial plants producing gluten and starch from wheat that are widely used in the food industry, meanwhile the fractions of fiber and bran are diverted to feed production.

Eliminating of gluten residue in wheat processing products allows produce gluten free starch and gluten free fraction of arabinoxylan and other non-starch polysaccharides, suitable for flour mixtures or bakery production for users intolerant to gluten or celiac sufferers.

The aim of the research was to use fermentation with Lactobacillus strains for elimination of gluten in wheat by-products.

\section{Materials and Methods}

Materials

Investigations were carried out at the Kaunas University of Technology, Food Institute, Lithuania. Samples of wheat fractions after dry and wet fractionation: starch, fiber and bran were provided by Roquette Amilina, AB, Lithuania.

A fraction of wheat bran was obtained as a by-product during the dry milling of wheat grain and was composed of outer layers of wheat kernel, mainly pericarp. A fraction of fiber was obtained as a by-product in the wet processing of the flour for starch and gluten separation, and was mainly composed of seed coat and aleurone residues.

\section{Physical-chemical analysis of composition of wheat} by-products

Moisture content of wheat by-products was measured by humidity measuring device Kern MLS 50-3HA 160N. $\mathrm{pH}$ was measured by $\mathrm{pH}$-meter ORION 3STAR.

Determination of protein content was done by Kjeldahl method (LST EN ISO 20483).

\section{Research on the selection of Lactobacillus strains}

Research to remove wheat gluten was carried out experimenting with microorganisms of the collection from the KTU Food Institute. Four probiotic strains: Lactobacillus plantarum P-1, Lactobacillus brevis R-1, Lactobacillus acidophilus 308, Lactobacillus acidophilus 336 were used.

The LAB cultures were stored for the study at $-72-74{ }^{\circ} \mathrm{C}$ in the VIABANK (MWE medical wire) system. Cultures revived in MRS broth (Biolife, Italy): 
an initial LAB suspension was prepared by seeding of the initial culture on MRS agar (Biolife, Italy) and incubating at $30^{\circ} \mathrm{C}$ (L. plantarum $\mathrm{P}-1$, L. brevis $\left.\mathrm{R}-1\right)$ and at $37^{\circ} \mathrm{C}$ (L. acidophilus 308, L. acidophilus 336) for $24 \mathrm{~h}$. Each LAB culture was transformed then into sterile milk and incubated at an appropriate temperature for $72 \mathrm{~h}$ under anaerobic conditions (aerostat with oxygen sorbent).

The number of lactic acid bacteria was determined by the method of seeding in Petri dishes by incubation on MRS agar under anaerobic conditions for $72 \mathrm{~h}$ at 30 or $37^{\circ} \mathrm{C}$.

Total plate count of samples performed according to standard procedures LST EN ISO 4833:2003, found $2.1 \times 10^{2} \mathrm{CFU} \mathrm{g}^{-1}$, count of yeast and mold $1.2 \times 10^{1} \mathrm{CFU} \mathrm{g}^{-1}$, aerobic and anaerobic spore forming bacteria was not found. The amounts of these microorganisms in the samples were small and the samples were suitable for consumption and biotechnological work without sterilization from the microbiological safety point of view.

Wheat starch or fiber samples $(5-10 \mathrm{~g})$ were weighed into glass tubes $(30 \mathrm{~mL})$, distilled water $(10 \mathrm{~mL})$ and LAB suspension $(7 \mathrm{~mL})$ at an active concentration of $1.7-2.8 \times 10^{6}$ was added (Table 1 ) and mixed well.

Preparing of samples of wheat product with different LAB strains

\begin{tabular}{|c|c|c|c|c|}
\hline \multirow{2}{*}{ Sample } & \multicolumn{2}{|c|}{$\begin{array}{c}\text { Wheat by- } \\
\text { product }\end{array}$} & \multirow{2}{*}{ LAB strains } & \multirow{2}{*}{$\begin{array}{l}\text { Active } \\
\text { concen- } \\
\text { tration, } \\
\text { CFU } \text { g }^{-1}\end{array}$} \\
\hline & $\begin{array}{c}\text { Starch, } \\
\text { g }\end{array}$ & $\begin{array}{c}\text { Fibre, } \\
\text { g }\end{array}$ & & \\
\hline SLA1 & 5 & - & $\begin{array}{l}\text { L. acidophilus } \\
308\end{array}$ & $2.0 \times 10^{6}$ \\
\hline SLA2 & 5 & - & $\begin{array}{l}\text { L. acidophilus } \\
336\end{array}$ & $2.1 \times 10^{6}$ \\
\hline SLB & 5 & - & L.brevis R-1 & $1.7 \times 10^{6}$ \\
\hline SLP & 5 & - & L.plantarum $\mathrm{P}-1$ & $2.8 \times 10^{6}$ \\
\hline FLA1 & - & 10 & $\begin{array}{l}\text { L. acidophilus } \\
308\end{array}$ & $2.0 \times 10^{6}$ \\
\hline FLA2 & - & 10 & $\begin{array}{l}\text { L. acidophilus } \\
336\end{array}$ & $2.1 \times 10^{6}$ \\
\hline FLB & - & 10 & L.brevis R-1 & $1.7 \times 10^{6}$ \\
\hline FLP & - & 10 & L.plantarum P-1 & $2.8 \times 10^{6}$ \\
\hline
\end{tabular}

LAB - lactic acid bacteria, SLA1 - starch with L. acidophilus 308; SLA2 - starch with L. acidophilus 336; SLB - starch with L. brevis R-1; SLP - starch with $L$. plantarum P-1; FLA1 - fiber with $L$. acidophilus 308; FLA2 - fiber with L. acidophilus 336; FLB - fiber with L. brevis R-1; FLP - fiber with L. plantarum $\mathrm{P}-1$

Samples were incubated at 30 and $37^{\circ} \mathrm{C}, \mathrm{pH}$ and gluten content in sourdough were measured after 12 and 24 hours.

\section{Gluten quantitation by ELISA}

Gluten residues in wheat products were quantitated by competitive ELISA using G12 antibody AACCI 38-52.01 (Romer Labs, UK Ltd) according to the manufacturer's instructions. Gluten concentrations were established based on calibration function provided by Romer Labs. Multiscan EX microplate reader with a $450 \mathrm{~nm}$ filter was used for the reading of the strips.

\section{Results and Discussion}

The fractions of starch, fiber and bran had different moisture content $(10.78-72.01 \%)$, different amount of total protein $(0.32-16.9 \%)$ an initial gluten concentration of $85-33750 \mathrm{mg} \mathrm{kg}^{-1}$ (Table 2).

For eliminating of gluten residues starch and fiber were fermented with four probiotic strains separately: Lactobacillus plantarum P-1, Lactobacillus brevis R-1, Lactobacillus acidophilus 308, Lactobacillus acidophilus 336. Short (12 hours) and long fermentation (24 hours) at 30 and $37^{\circ} \mathrm{C}$ was used.

Table 2

\section{Characteristics of samples}

\begin{tabular}{lccl}
\hline $\begin{array}{l}\text { Wheat } \\
\text { by- } \\
\text { products }\end{array}$ & $\begin{array}{c}\text { Moisture, } \\
\mathbf{\%}\end{array}$ & $\begin{array}{c}\text { Total } \\
\text { protein, } \\
\mathbf{\%}\end{array}$ & $\begin{array}{c}\text { Gluten content, } \\
\text { mg kg-1 }\end{array}$ \\
\hline Fiber* & $72.01 \pm 0.20$ & $3.80 \pm 0.02$ & $7800.00 \pm 218.00$ \\
Bran** & $13.43 \pm 0.20$ & $16.90 \pm 0.02$ & $33750.00 \pm 945.00$ \\
Starch & $10.78 \pm 0.20$ & $0.32 \pm 0.02$ & $85.00 \pm 2.00$ \\
\hline
\end{tabular}

* Outer layers of wheat kernel, mainly pericarp.

** Seed coat and aleurone residues.

The reducing of gluten content depending on the decrease of $\mathrm{pH}$ was observed. Gerez et al. (2008), Rollan et al. (2016) demonstrated also that protein hydrolysis in sourdough were partially caused by $\mathrm{pH}$-dependent activation of cereal enzymes according to change in proteolytic activity. Di Cagno et al. (2002) proved also, that primary proteolysis is exerted by wheat endogenous enzymes, which are activated by the low $\mathrm{pH}$. Among the selected LAB cultures, the lowest $\mathrm{pH}$ was achieved by using L. acidophilus 308, the least acidic sourdough was obtained with L. brevis $\mathrm{R}-1$. The $\mathrm{pH}$ of the fermentation of starch was also lower than sourdough of fiber (Figure 1).

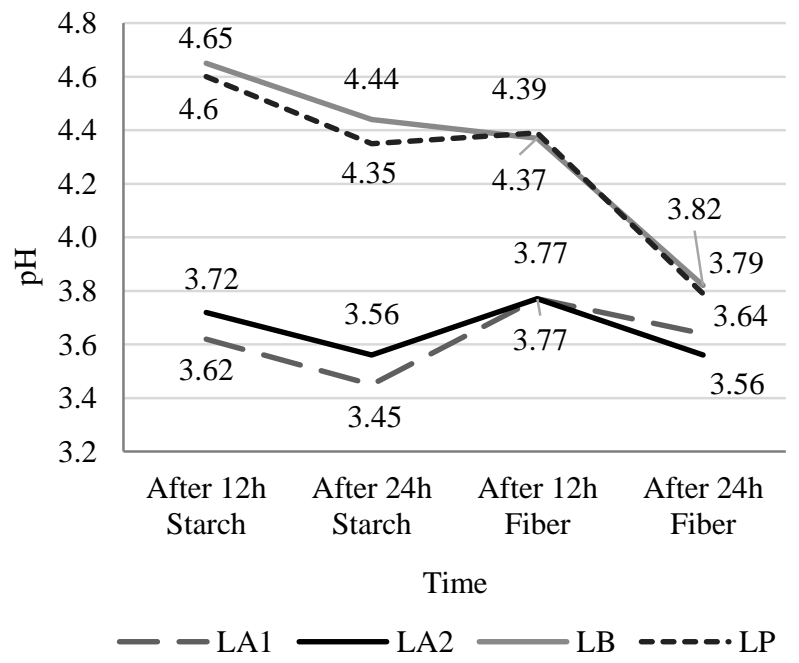

Figure 1. Decreasing of pH in different sourdough LA1 - L. acidophilus 308; LA2 - L. acidophilus 336; LB L. brevis $R-1$; LP - L. plantarum $P-1$

Further hydrolysis of peptides was exerted by intracellular peptidases of LAB in a strain-specific manner: the type and amount of released amino acids depend on the fermenting strain (Di Cagno et al., 2002). 
pH and gluten content in samples of wheat starch after fermentation

Table 3

\begin{tabular}{|c|c|c|c|c|c|}
\hline \multirow{3}{*}{ Samples } & \multirow{3}{*}{ Temperature, ${ }^{\circ} \mathbf{C}$} & \multicolumn{4}{|c|}{ Duration of fermentation, $h$} \\
\hline & & \multicolumn{2}{|r|}{12} & \multicolumn{2}{|r|}{24} \\
\hline & & pH & Gluten content, $\mathrm{mg} \mathrm{kg}^{-1}$ & pH & Gluten content, $\mathrm{mg} \mathrm{kg}^{-1}$ \\
\hline SLA1 & 37 & $3.62 \pm 0.02$ & $25.00 \pm 0.60$ & $3.45 \pm 0.02$ & $12.00 \pm 0.30$ \\
\hline SLA2 & 37 & $3.72 \pm 0.02$ & $28.00 \pm 0.70$ & $3.56 \pm 0.02$ & $26.00 \pm 0.70$ \\
\hline SLB & 30 & $4.65 \pm 0.02$ & $36.00 \pm 0.90$ & $4.44 \pm 0.02$ & $30.00 \pm 0.80$ \\
\hline SLP & 30 & $4.60 \pm 0.02$ & $20.00 \pm 0.50$ & $4.35 \pm 0.02$ & $15.00 \pm 0.40$ \\
\hline
\end{tabular}

SLA1 - starch with L. acidophilus 308; SLA2 - starch with L. acidophilus 336; SLB - starch with L. brevis R-1; SLP - starch with L. plantarum $\mathrm{P}-1$

Table 4

pH and gluten content in samples of wheat fiber after fermentation

\begin{tabular}{|c|c|c|c|c|c|}
\hline \multirow{3}{*}{ Samples } & \multirow{3}{*}{ Temperature, ${ }^{\circ} \mathrm{C}$} & \multicolumn{4}{|c|}{ Duration of fermentation, $h$} \\
\hline & & \multicolumn{2}{|r|}{12} & \multicolumn{2}{|r|}{24} \\
\hline & & pH & Gluten content, mg kg ${ }^{-1}$ & pH & Gluten content, $\mathrm{mg} \mathrm{kg}^{-1}$ \\
\hline FLA1 & 37 & $3.77 \pm 0.02$ & $4500.00 \pm 126.00$ & $3.64 \pm 0.02$ & $2450.00 \pm 67.00$ \\
\hline FLA2 & 37 & $3.77 \pm 0.02$ & $4650.00 \pm 130.00$ & $3.56 \pm 0.02$ & $2200.00 \pm 62.00$ \\
\hline FLB & 30 & $4.37 \pm 0.02$ & $5100.00 \pm 143.00$ & $3.82 \pm 0.02$ & $2810.00 \pm 79.00$ \\
\hline FLP & 30 & $4.39 \pm 0.02$ & $4700.00 \pm 132.00$ & $3.79 \pm 0.02$ & $2500.00 \pm 70.00$ \\
\hline
\end{tabular}

FLA1 - fiber with L. acidophilus 308; FLA2 - fiber with L. acidophilus 336; FLB - fiber with L. brevis R-1; FLP - fiber with L. plantarum $\mathrm{P}-1$

The selected strains exhibited different proteolytic activity in this research, which leads to a reduction of gluten content in wheat sourdoughs. The amount of nondigestible gluten peptides decreased in all fermented starch samples after $12 \mathrm{~h}$, but the most pronounced proteolytic effect was observed in sourdough with L. Plantarum P-1 (Table 3).

After 24 hours the lowest amount of immunoreactive gluten peptides was found in sourdough with L. acidophilus 308 and L. Plantarum P-1. Sourdough fermentation decreases the disulphide bonds in gluten network, which influence its digestibility in people with gluten sensitivity (Gänzle et al, 2008). Although fermentation of starch with L. acidophilus 336 most reduced $\mathrm{pH}$, failed to reduce the gluten content to $20 \mathrm{mg} \mathrm{kg}^{-1}$. Fiber of wheat (after wet fractionation) had a high initial content of gluten (up to $33750 \mathrm{mg} \mathrm{kg}^{-1}$ ).

Despite a significant decrease in $\mathrm{pH}$ after fermentation with LAB the amount of gluten was reduced but remained still high (Table 4). The results showed that LAB fermentation can only eliminate small amounts of gluten while content of gluten at high concentrations still remains high after hydrolysis. Similar results were obtained by hydrolysis of fermentation of wheat flour. In the wheat flour $74590-80127 \mathrm{mg} \mathrm{kg}^{-1}$ of gluten were found (Greco et al., 2011). Results achieved in the studies (De Angelis et al., 2006; Stefańska et al., 2016) demonstrate that the proteolytic activity of the selected LAB strains is not high enough to allow their use for the degradation of allergenic proteins in bakery products made from wheat flour intended for patients with food allergy to gluten. Fermentation with LAB, however, could be used in production from raw materials with low gluten content and, at high concentrations, their effects must be combined with proteolytic effects of the enzymes.

\section{Conclusions}

The role of a fermentation process for improving the quality of GF products and developing a new concept of GF products is very important, however, this method is not suitable to completely degrade gluten, when its initial amount in the raw material is high.

Gluten could be degraded in wheat starch to levels below $20 \mathrm{mg} \mathrm{kg}^{-1}$ by application of Lactobacillus plantarum $\mathrm{P}-1$ in a short time period, and L. acidophilus 308 after a long fermentation. These selected LAB strains may be applied as the specific starter cultures to prepare bakery products of special nutritional use from wheat starch, but do not reduce the amount of gluten in fiber and bran to a safe limit for gluten-free diet.

\section{Acknowledgment}

The authors thank Roquette Amilina, $\mathrm{AB}$ for the samples of wheat processing products: fractions of starch, fiber and bran.

\section{References}

1. Catassi C., Gatti S., Fasano A. (2014) The new epidemiology of celiac disease. Journal of Pediatric Gastroenterology and Nutrition, Vol. 59, p. 7-9.

2. Czuchajowska Z., Pomeranz Y. (1993) Protein concentrates and prime starch from wheat flours. Cereal Chemistry, Vol. 70 (6), p. 701-706.

3. De Angelis M., Rizzello C.G., Fasano A., Clemente M.G., De Simone C., Silano M., De Vincenzi M., Losito I., Gobbetti M. (2006) VSL\# 3 probiotic preparation has the capacity to hydrolyze gliadin polypeptides responsible for celiac sprue probiotics and gluten intolerance. Biochimica et Biophysica Acta (BBA) Molecular Basis of Disease, Vol. 1762(1), p. 80-93.

4. De Palma G., Cinova J., Stepankova R., Tuckova L., Sanz Y. (2010) Pivotal Advance: Bifidobacteria and gram-negative bacteria differentially influence immune 
responses in the proinflammatory milieu of celiac disease. Journal of Leukocyte Biology, Vol. 87(5), p. 765-778.

5. Di Cagno R., De Angelis M., Auricchio S., Greco L., Clarke C., De Vincenzi M., Giovannini C., D’Archivio M., Landolfo F., Parrilli G., Minervini F., Arendt E. Gobbetti M. (2004) Sourdough bread made from wheat and nontoxic flours and started with selected Lactobacilli is tolerated in celiac sprue patients. Applied and Environmental Microbiology, Vol. 70, p. 1088-1096.

6. Di Cagno R., De Angelis M., Lavermicocca P., De Vincenzi M., Giovannini C., Faccia M., Gobbetti M. (2002) Proteolysis by sourdough lactic acid bacteria: effects on wheat flour protein fractions and gliadin peptides involved in human cereal intolerance. Applied and Environmental Microbiology, Vol. 68(2), p. 623-633.

7. Di Cagno R., Rizzello C.G., De Angelis M., Cassone A., Giuliani G., Benedusi A., Gobbetti M. (2008) Use of selected sourdough strains of Lactobacillus for removing gluten and enhancing the nutritional properties of glutenfree bread. Journal of Food Protection, Vol. 71(7), p. 1491-1495.

8. Do Nascimento A.B., Fiates G.M.R., Teixeira E. (2017) We want to be normal! Perceptions of a group of Brazilian consumers with coeliac disease on gluten-free bread buns. International Journal of Gastronomy and Food Science, Vol. 7, p. 27-31.

9. Gänzle M. G., Loponen J., Gobbetti M. (2008) Proteolysis in sourdough fermentations: mechanisms and potential for improved bread quality. Trends in Food Science \& Technology, Vol. 19 (10), p. 513-521.

10. Gerez C. L., Dallagnol A., Rollán G., de Valdez G. F. (2012) A combination of two lactic acid bacteria improves the hydrolysis of gliadin during wheat dough fermentation. Food Microbiology, Vol. 32(2), p. 427-430.

11. Giuliani G., Benedusi A., Di Cagno R., Rizzello C. G., De Angelis M., Gobbetti M., Cassone A. (2016) U.S. Patent No. 9,386,777. Washington, DC: U.S. Patent and Trademark Office.

12. Greco L., Gobbetti M., Auricchio R., Di Mase R., Landolfo F., Paparo F., Terrone G. (2011) Safety for patients with celiac disease of baked goods made of wheat flour hydrolyzed during food processing. Clinical Gastroenterology and Hepatology, Vol. 9 (1), p. 24-29.

13. Guerzoni M. E., Gianotti A., Serrazanetti D. I. (2011) Fermentation as a tool to improve healthy properties of bread. In: Flour and breads and their fortification in health and disease prevention. London: Academic Press, p. 385-393.

14. Gujral N., Freeman H., Thomson A. (2012) Celiac disease: Prevalence, diagnosis, pathogenesis and treatment. World Journal of Gastroenterology, Vol. 18 (42), p. 6036-6059.

15. Hager A. S., Wolter A., Czerny M., Bez J., Zannini E., Arendt E. K., Czerny M. (2012). Investigation of product quality, sensory profile and ultrastructure of breads made from a range of commercial gluten-free flours compared to their wheat counterparts. European Food Research and Technology, Vol. 235 (2), p. 333-344.

16. Kang J. Y., Kang A. H. Y., Green A., Gwee K. A., Ho K. Y. (2013) Systematic review: worldwide variation in the frequency of coeliac disease and changes over time. Alimentary Pharmacology \& Therapeutics, Vol. 38(3), p. 226-245.

17. Katina K., Arendt E., Liukkonen K. H., Autio K., Flander L., Poutanen K. (2005) Potential of sourdough for healthier cereal products. Trends in Food Science \& Technology, Vol. 16 (1-3), p. 104-112.

18. Loponen J., Sontag-Strohm T., Venäläinen J., Salovaara H. (2007) Prolamin hydrolysis in wheat sourdoughs with differing proteolytic activities. Journal of Agricultural and Food Chemistry, Vol. 55 (3), p. 978-984.

19. Miranda J., Lasa A., Bustamante M. A., Churruca I., Simon E. (2014). Nutritional differences between a gluten-free diet and a diet containing equivalent products with gluten. Plant Foods for Human Nutrition, Vol. 69 (2), p. 182-187.

20. Moroni A. V., Dal Bello F., Arendt E.K. (2009) Sourdough in gluten-free bread-making: an ancient technology to solve a novel issue? Food Microbiology, Vol. 26(7), p. 676-684.

21. Nionelli L., Rizzello C. G. (2016) Sourdough-based biotechnologies for the production of gluten-free foods. Foods, Vol. 5(3), p. 65-79.

22. Pellegrini N., Agostoni C. (2015) Nutritional aspects of gluten-free products. Journal of the Science of Food and Agriculture, Vol. 95 (12), p. 2380-2385.

23. Rizzello C. G., De Angelis M., Di Cagno R., Camarca A., Silano M., Losito I., Gianfrani C. (2007) Highly efficient gluten degradation by lactobacilli and fungal proteases during food processing: new perspectives for celiac disease. Applied and Environmental Microbiology, Vol. 73 (14), p. 4499-4507.

24. Rizzello C. G., Curiel J. A., Nionelli L., Vincentini O., Di Cagno R., Silano M., Coda R. (2014) Use of fungal proteases and selected sourdough lactic acid bacteria for making wheat bread with an intermediate content of gluten. Food Microbiology, Vol. 37, p. 59-68.

25. Rollan G., De Angelis M., Gobbetti M., De Valdez G. F. (2005) Proteolytic activity and reduction of gliadin-like fractions by sourdough lactobacilli. Journal of Applied Microbiology, Vol. 99(6), p. 1495-1502.

26. Romanová K., Urminská D. (2017) Potential of Lactobacillus plantarum CCM 3627 and Lactobacillus brevis CCM 1815 for fermentation of cereal substrates. Potravinarstvo Slovak Journal of Food Sciences, Vol. 11 (1), p. 544-549.

27. Sakandar H.A., Usman K. and Imran M. (2018) Isolation and characterization of gluten-degrading Enterococcus mundtii and Wickerhamomyces anomalus, potential probiotic strains from indigenously fermented sourdough (Khamir). LWT Food Science and Technology, Vol. 91, p. 271-277.

28. Standard 118-1979 (2015) Codex Alimentarius Commission. Revision 1, Amendment 2. [accessed on 04.12.2018.]. Available at: http://www.codex alimentarius.net/download/standards/291/cxs_118e.pdf

29. Stefańska I., Piasecka-Jóźwiak K., Kotyrba D., Kolenda M., Stecka K. M. (2016) Selection of lactic acid bacteria strains for the hydrolysis of allergenic proteins of wheat flour. Journal of the Science of Food \& Agriculture, Vol. 96 (11), p. 3897-3905.

30. Stevens L. and Rashid M. (2008) Gluten-free and regular foods: a cost comparison. Canadian Journal of Dietetic Practice and Research, Vol. 69 (3), p. 147-150.

31. Thompson T., Dennis M., Higgins L. A., Lee A. R., Sharrett M. K. (2005) Gluten-free diet survey: are Americans with coeliac disease consuming recommended amounts of fibre, iron, calcium and grain foods? Journal of Human Nutrition and Dietetics, Vol. 18(3), p. 163-169.

32. Thiele C., Grassl S., Gänzle M. (2004) Gluten hydrolysis and depolymerization during sourdough fermentation. Journal of Agricultural and Food Chemistry, Vol. 52(5), p. 1307-1314.

33. Van Den Broeck H. C., Van Herpen T. W., Schuit C., Salentijn E. M., Dekking L., Bosch D., Van Der Meer I. M. (2009) Removing celiac disease-related gluten proteins from bread wheat while retaining technological 
properties: a study with Chinese spring deletion lines. BMC Plant Biology, Vol. 9(1), p. 41.

34. Vermeulen N., Kretzer J., Machalitza H., Vogel R. F., Gänzle M. G. (2006) Influence of redox-reactions catalysed by homo-and hetero-fermentative lactobacilli on gluten in wheat sourdoughs. Journal of Cereal Science, Vol. 43 (2), p. 137-143.

35. Vukotić G., Strahinić I., Begović J., Lukić J., Kojić M., Fira D. (2016) Survey on proteolytic activity and diversity of proteinase genes in mesophilic Lactobacilli. Microbiology, Vol. 85 (1), p. 33-41.

36. Wild D., Robins G. G., Burley V. J., Howdle P. D. (2010) Evidence of high sugar intake, and low fibre and mineral intake, in the gluten-free diet. Alimentary Pharmacology \& Therapeutics, Vol. 32 (4), p. 573-581.
37. Mixture of at least 6 species of lactic acid bacteria and/or bifidobacteria in the manufacture of sourdough (2006). [accessed on 08.11.2018.]. Available at: https://patents.google.com/patent/WO2006097415A1/en

38. Yin, Y., Wang, J., Yang, S., Feng, J., Jia, F., Zhang, C. (2015) Protein degradation in wheat sourdough fermentation with Lactobacillus plantarum M616. Interdisciplinary Sciences: Computational Life Sciences, Vol. 7 (2), p. 205-210. 